OPEN ACCESS

Edited by: Michael H. Perlin,

University of Louisville, USA

Reviewed by: Bjorn Sandrock,

University of Marburg, Germany Michael E. Hood,

Amherst College, USA

*Correspondence.

Sanushka Naidoo

sanushka.naidoo@up.ac.za

†These authors have contributed equally to this work

Specialty section: This article was submitted to Fungi and Their Interactions,

a section of the journal

Frontiers in Microbiology

Received: 16 August 2016 Accepted: 21 November 2016 Published: 08 December 2016

Citation:

Mangwanda $R$, Zwart $L$ van der Merwe NA, Moleleki LN,

Berger DK, Myburg AA and

Naidoo S (2016) Localization and Transcriptional Responses of Chrysoporthe austroafricana in Eucalyptus grandis Identify Putative

Pathogenicity Factors.

Front. Microbiol. 7:1953. doi: 10.3389/fmicb.2016.01953

\section{Localization and Transcriptional Responses of Chrysoporthe austroafricana in Eucalyptus grandis Identify Putative Pathogenicity Factors}

\author{
Ronishree Mangwanda ${ }^{1 \dagger}$, Lizahn Zwart ${ }^{1 \dagger}$, Nicolaas A. van der Merwe ${ }^{1}$, \\ Lucy Novungayo Moleleki², Dave Kenneth Berger' ${ }^{3}$, Alexander A. Myburg ${ }^{1}$ and \\ Sanushka Naidoo ${ }^{1 *}$
}

\footnotetext{
'Department of Genetics, Forestry and Agricultural Biotechnology Institute, Genomics Research Institute, University of Pretoria, Pretoria, South Africa, ${ }^{2}$ Department of Microbiology and Plant Pathology, Forestry and Agricultural Biotechnology Institute, University of Pretoria, Pretoria, South Africa, ${ }^{3}$ Department of Plant and Soil Sciences, Forestry and Agricultural Biotechnology Institute, Genomics Research Institute, University of Pretoria, Pretoria, South Africa
}

Chrysoporthe austroafricana is a fungal pathogen that causes the development of stem cankers on susceptible Eucalyptus grandis trees. Clones of E. grandis that are partially resistant and highly susceptible have been identified based on the extent of lesion formation on the stem upon inoculation with $C$. austroafricana. These interactions have been used as a model pathosystem to enhance our understanding of interactions between pathogenic fungi and woody hosts, which may be different to herbaceous hosts. In previous research, transcriptomics of host responses in these two clones to C. austroafricana suggested roles for salicylic acid and gibberellic acid phytohormone signaling in defense. However, it is unclear how the pathogen infiltrates host tissue and which pathogenicity factors facilitate its spread in the two host genotypes. The aim of this study was to investigate these two aspects of the E. grandis-C. austroafricana interaction and to test the hypothesis that the pathogen possesses mechanisms to modulate the tree phytohormone-mediated defenses. Light microscopy showed that the pathogen occurred in most cell types and structures within infected $E$. grandis stem tissue. Notably, the fungus appeared to spread through the stem by penetrating cell wall pits. In order to understand the molecular interaction between these organisms and predict putative pathogenicity mechanisms of $C$. austroafricana, fungal gene expression was studied in vitro and in planta. Fungal genes associated with cell wall degradation, carbohydrate metabolism and phytohormone manipulation were expressed in planta by $C$. austroafricana. These genes could be involved in fungal spread by facilitating cell wall pit degradation and manipulating phytohormone mediated defense in each host environment, respectively. Specifically, the in planta expression of an ent-kaurene oxidase and salicylate hydroxylase in C. austroafricana suggests putative mechanisms by which the pathogen can modulate the phytohormone-mediated defenses of 
the host. These mechanisms have been reported in herbaceous plant-pathogen interactions, supporting the notion that these aspects of the interaction are similar in a woody species. This study highlights ent-kaurene oxidase and salicylate hydroxylase as candidates for further functional characterization.

Keywords: fungal pathogenicity, dual RNA-sequencing, cell wall degrading enzymes, hormone signaling

\section{INTRODUCTION}

The value of model plant-pathogen systems for studying the complexities of plant defense is undeniable. However, most of the current knowledge regarding plant defense originates from research conducted in established model systems with herbaceous plants such as Nicotiana spp. and Arabidopsis thaliana (Tsuda and Somssich, 2015), and model systems with woody perennials are scarce. To expand this niche, the interaction of Eucalyptus grandis and Chrysoporthe austroafricana has been established as a model system.

The fungal pathogen $C$. austroafricana causes the development of stem cankers on susceptible E. grandis trees (Roux et al., 2003). It was first discovered in the late 1980s (Wingfield et al., 1989). The pathogen was previously described as Chrysoporthe cubensis, but reclassified when phylogenetic and morphological analyses showed that it was a different species (Myburg et al., 2002; Gryzenhout et al., 2004). In South Africa, C. austroafricana may have undergone a host shift from native Syzygium spp. to non-native Eucalyptus (Heath et al., 2006; Wingfield et al., 2008). Damage to plantations caused by this pathogen has largely been limited through the use of E. grandis $x$ E. urophylla hybrids that exhibit increased disease resistance.

Chrysoporthe austroafricana is pathogenic on E. grandis and exhibits different levels of virulence in the clones TAG5 and ZG14, with longer lesions in ZG14 compared to TAG5 (van Heerden et al., 2005; Naidoo et al., 2013). The clone ZG14 has high mortality rates after infection, while lesions are confined in TAG5. Therefore, the clones are considered highly susceptible and moderately resistant to the pathogen, respectively. This pathosystem has been exploited as a model system to study host-pathogen interactions in woody plants. Very little is known about the physical location and pathogenicity mechanisms of C. austroafricana within this host. The spread of wood-rotting fungi and various host defense mechanisms against them have been described (Pearce, 1996). Some of these fungi are able to spread by degrading cell walls, while those that lack this ability spread through weak points in the cell wall like pits and perforation plates (Pearce, 1996). However, to our knowledge, the spread of non-wood-rotting putative necrotrophs that proliferate in woody stem tissue has not been described. Pathogen spread would also be influenced by the response of the host to the pathogenicity strategy of the pathogen. Given the development of longer lesions on the stems of ZG14 compared to TAG5 (Naidoo et al., 2013), we hypothesize that pathogen spread would be faster in ZG14 than in TAG5.

In previous work, we examined the expression and hormone profiles of TAG5 and ZG14 in response to challenge with C. austroafricana at 3 days post-inoculation (Naidoo et al., 2013;
Mangwanda et al., 2015). While genes involved in cell wall modifications and response to oxidative stress were common between the hosts, hormone signaling seemed to facilitate resistance in TAG5. One of the main findings was that basal levels of salicylic acid were significantly higher in TAG5 compared to ZG14, with SA marker gene expression profiles supporting this finding. TAG5 displayed a decrease in gibberellic acid (GA) levels following inoculation and this phenomenon was not apparent in ZG14 (Mangwanda et al., 2015). This initial investigation revealed that the woody perennial had a similar defense mechanism to that found in herbaceous systems. For example, it was found that high levels of SA contribute to resistance in tobacco (Verberne et al., 2000) and that GA has a negative effect on resistance in rice (Qin et al., 2012; Yang et al., 2016). Furthermore, the results suggest that C. austroafricana encounters two different host environments, and we hypothesize that the fungus employs different mechanisms to respond to the phytohormone signaling and other defenses in each host.

Previous studies showed that the stress induced by growing the pathogen in vitro on nutrient limiting media can result in the expression of genes associated with pathogenicity (Hottes et al., 2004; Bruno et al., 2010). The rationale is that the nutrient limiting medium presents a stressful environment for the pathogen, a proxy for the harsh in planta environment that it would encounter during the early stages of infection, and would thus induce similar pathogenicity mechanisms. Apart from in vitro assays, in planta expression of pathogenicity genes can be studied using dual RNA-sequencing, a powerful tool for capturing responses of the pathogen in direct contact with host tissue (Westermann et al., 2012; Hayden et al., 2014).

The aim of this study was to examine putative mechanisms by which C. austroafricana causes disease in E. grandis. To achieve this, we tracked pathogen spread using light microscopy and studied the transcriptional responses of the pathogen within the two host environments.

\section{MATERIALS AND METHODS}

\section{Microscopy}

Stems of 2-3 year old E. grandis clones TAG5 and ZG14, which are moderately resistant and highly susceptible, respectively, were inoculated with C. austroafricana as described previously (Mangwanda et al., 2015). A $5 \mathrm{~mm}$ diameter section of bark was removed with a cork borer $30 \mathrm{~cm}$ above the base of the stem. The plant was inoculated by inserting an agar plug covered in actively growing mycelium of the type isolate of C. austroafricana (Forestry and Agricultural Biotechnology Institute culture collection, CMW2113; Centraalbureau voor 


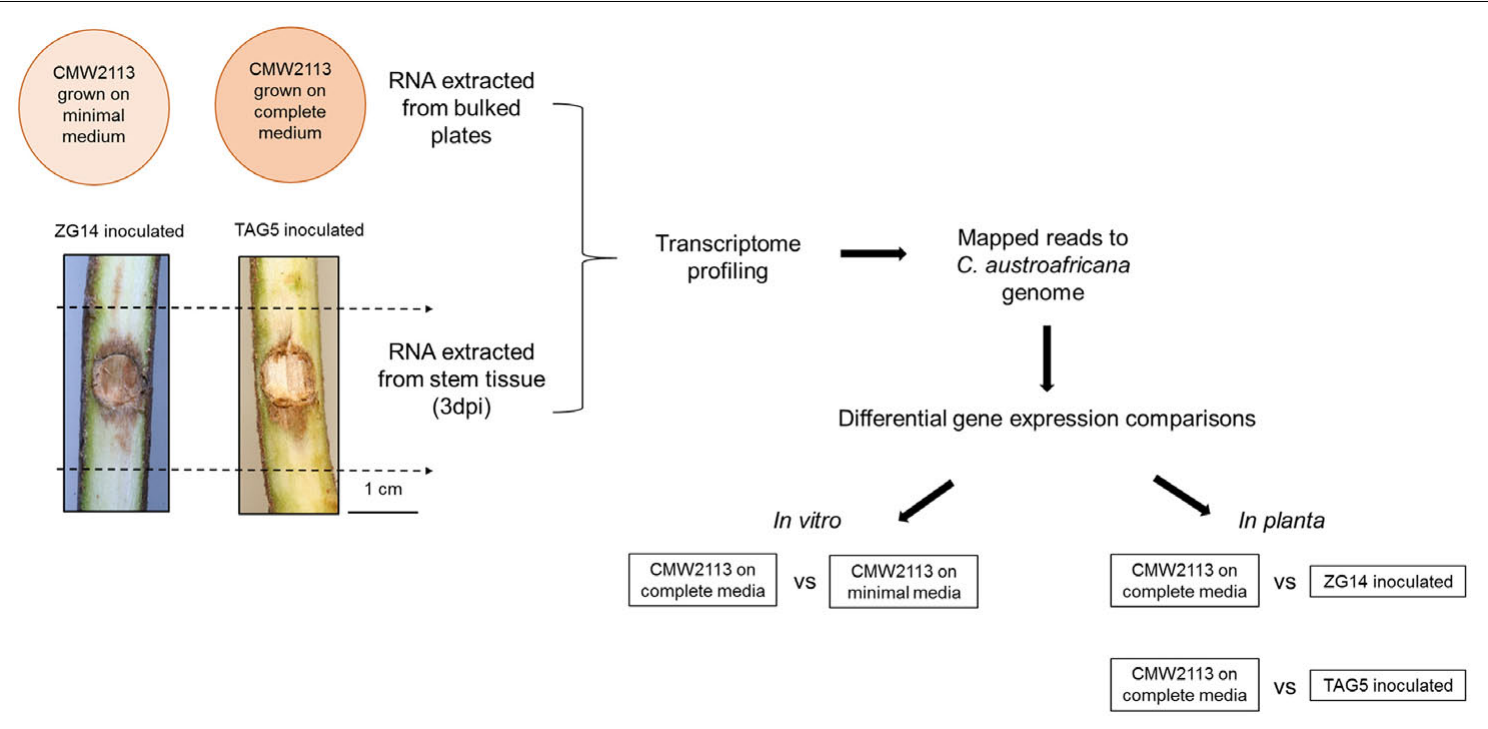

FIGURE 1 | Schematic representation of the transcriptome profiling performed for Chrysoporthe austroafricana. CMW2113 represents the type isolate of $C$. austroafricana.

Schimmelcultures KNAW Fungal Biodiversity Center - CBS 112916, Agricultural Research Council National Collection of Fungi - PREM 58023, dried culture) in the wound. The section of bark was placed on the agar plug and the wound was sealed with Parafilm (Sigma-Aldrich). After 3, 7, 14, 21, and 42 days, small pieces of $E$. grandis stem were excised at the inoculation site, trimmed and fixed in FAA (45\% ethanol, 5\% acetic acid, and $5 \%$ formalin in distilled water). The samples were sectioned with a sliding microtome (approximately $15 \mu \mathrm{m}$ thick) or dehydrated with a butanol series, embedded in paraffin wax (Sigma-Aldrich, Supplementary Table S7) and sectioned with a rotary microtome (8-10 $\mu \mathrm{m}$ thick). Sections were stained with Safranin O (uniLAB) and Fast Green FCF (uniLAB) and mounted in Entellan (Merck Millipore), or stained with and mounted in lactophenol blue solution (Fluka, Sigma-Aldrich).

\section{Transcriptome Sequencing of C. austroafricana In vitro and In planta Culturing of $C$. austroafricana In vitro}

The type isolate of C. austroafricana (CMW2113) was cultured on complete and minimal media (Leslie, 2007) covered with a nylon membrane disk (Sigma-Aldrich, $0.45 \mu \mathrm{m}$ ). Plates $(90 \mathrm{~mm}$ diameter) were incubated at $28^{\circ} \mathrm{C}$ until the mycelial mat covered the nylon membrane (Figure 1). Three independent biological replicates each were used for complete and minimal media. Mycelium was harvested, bulked and frozen in liquid nitrogen. RNA was extracted using the Plant/Fungi total RNA purification kit (Norgen Biotek, Sigma-Aldrich), treated with RNase-free DNaseI enzyme (Qiagen, Inc., Valencia, CA, USA) and purified using the RNeasy ${ }^{\circledR}$ MinElute Kit (Qiagen, Inc., Valencia, CA, USA) according to the manufacturer's protocol. RNA was sent to the Beijing Genome Institute (BGI) for TruSeq using the Illumina Genome Analyser with a 50 bp paired end module (Illumina, San Diego, CA, USA).

\section{In planta Expression of C. austroafricana Genes}

Eucalyptus grandis genotypes TAG5 and ZG14 were inoculated with C. austroafricana CMW2113 as described by Mangwanda et al. (2015). Inoculated and control stem material was harvested with three independent biological replicates consisting of three ramets each, at 3 days post-inoculation (Figure 1). RNA was extracted from these samples as indicated in Mangwanda et al. (2015) and sent to the BGI for transcriptome profiling using the Illumina Genome Analyser with a 50 bp paired end module (Illumina, San Diego, CA, USA).

\section{Bioinformatics Analysis C. austroafricana Genome Annotation}

Putative predictions for C. austroafricana gene models (GenBank JYIP00000000; Wingfield et al., 2015) were searched for with the BLASTX algorithm against the GenBank NR database (evalue > 1e-10) using Blast2GO (Conesa and Gotz, 2008). This software was additionally used to assign GO (Gene Ontologies) and KEGG (Kyoto Encyclopedia of Genes and Genomes) annotations to the predicted genes. Further putative functions such as pathogenicity, reduced virulence, lethality and increased virulence were assessed using a BLASTP (e-value > 1e-5) against the PHI-database (Winnenburg et al., 2006). A BLASTP analysis against the Carbohydrate-Active enZyme (CAZymes) database ${ }^{1}$ was performed with an e-value $<1 \mathrm{e}^{-2}$, a bit score threshold of 55 and a rule level of support of 40 .

\section{Read Mapping and Transcript Quantification}

RNA reads obtained from BGI were analyzed using the Galaxy platform (Giardine et al., 2005; Blankenberg et al., 2010; Goecks et al., 2010). The quality of the reads was assessed using FASTQC v0.5 and FASTQ groomer v1.0.4. Mapping of the reads was

\footnotetext{
${ }^{1}$ http://www.cazy.org
} 
performed against the C. austroafricana genome and E. grandis genome using the TopHat v2.0.4 package. Thereafter, Cufflinks v1.03 was used to quantify the transcript abundance.

\section{Differential Gene Expression}

Differential gene expression of the in vitro and in planta samples was determined using Cuffdiff v1.0.3 (FPKM > 100). The following comparisons were made: complete medium vs. minimal medium, complete medium vs. C. austroafricana genes expressed in TAG5 inoculated samples and complete medium vs. C. austroafricana genes expressed in ZG14 inoculated samples (Figure 1). GO enrichment analysis was performed using Fisher's exact test $(p$-value $<0.05)$ in Blast2GO.

\section{Quantitative Real Time PCR Validation}

Primers for quantitative polymerase chain reaction (qPCR) analysis were designed using Primer3 v0.4, and their specificity verified using NCBI-Primer BLAST to detect any cross-species hybridization. In addition, the primers were validated using a BLASTN algorithm in a local blast on CLC Genomics Workbench $^{2}$ against the $C$. austroafricana genome and the genome of a well-known eucalypt endophyte, Botryosphaeria dothidea. First strand cDNA synthesis was performed using the Transcriptor First Strand cDNA Synthesis Kit (Roche, Mannheim, Germany) according to the manufacturer's protocol.

Quantitative PCR was performed on the QuantStudio ${ }^{\text {TM }}$ 12K Flex Real-Time PCR System (Applied Biosystems ${ }^{\circledR}$, Life Technologies, Inc.). The reaction consisted of the following reagents: primers $(0.3 \mu \mathrm{M}), \mathrm{SYBR}^{\circledR}$ Select Master Mix $(2 \mathrm{X}, 5 \mu \mathrm{l})$, and cDNA $(1 \mu \mathrm{l})$, in a total reaction of volume of $10 \mu \mathrm{l}$. All reactions were performed in triplicate. The following PCR protocol was used: $50^{\circ} \mathrm{C}$ for $2 \mathrm{~min}, 95^{\circ} \mathrm{C}$ for $10 \mathrm{~min}, 40$ cycles of $95^{\circ} \mathrm{C}$ for $15 \mathrm{~s}$ and $58^{\circ} \mathrm{C}$ for $1 \mathrm{~min}$. Melting curve analysis involved one cycle of $95^{\circ} \mathrm{C}$ for $15 \mathrm{~s}, 60^{\circ} \mathrm{C}$ for $1 \mathrm{~min}$ and a dissociation cycle of $95^{\circ} \mathrm{C}$ for $15 \mathrm{~s}$. Relative expression and normalization were performed using $q B A S E$ plus v1.0. The candidate reference genes, g10189 (unknown) and g1986 (vacuolar protein sortingassociated protein) were stably expressed in vitro and in planta. The Student's $t$-test $(p<0.05)$ was applied to test for significance between samples.

\section{RESULTS}

\section{Macroscopic Changes during Infection of $E$. grandis with C. austroafricana}

The macroscopic changes in the stems of E. grandis clones during infection with $C$. austroafricana were documented over a period of 6 weeks. Inoculated ramets were compared to mock inoculated and unwounded plants. Characteristic brown lesions were observed from 3 dpi (days post-inoculation) to $42 \mathrm{dpi}$ in both TAG5 (moderately resistant) and ZG14 (susceptible) plants (Figure 2) and were consistent with previous reports (Heath et al., 2006; Mangwanda et al., 2015). Lesion development occurred

${ }^{2}$ www://clcbio.com most rapidly in the axial direction, followed by radial and tangential spread (Figure 2). By 42 dpi, radial lesion development at the inoculation site was also slower in TAG5 than ZG14 (Figures 2D,E). In addition to lesion development, the inoculated plants exhibited an increasing number of symptoms indicative of wilting as infection progressed; the leaves of some ZG14 plants had died by $42 \mathrm{dpi}$, while the leaves of TAG5 plants were as healthy as controls (Figures $\mathbf{2 G}, \mathbf{H}$ ). No wilting was observed in wounded plants.

\section{The Location of C. austroafricana in Stem Tissue of Its Host, E. grandis}

While the macroscopic symptoms of C. austroafricana stem canker disease in Eucalyptus have been observed previously, the physical interaction and spread of the pathogen within its host have not yet been described. In order to achieve this, sections of E. grandis stem tissue at the inoculation site were stained with lactophenol blue (LBO) or Safranin O and Fast Green, and examined using light microscopy.

The anatomy of the E. grandis plants was consistent with previous descriptions of this genus (Chattaway, 1953). Soon after inoculation ( $3 \mathrm{dpi}$ ), hyphae could be detected in xylem vessels, between xylem fibers, in axial xylem parenchyma/vasicentric tracheids, and in direct contact with xylem ray parenchyma cells and phloem crystalliferous parenchyma (Figures 3 and 4). In the bark, hyphae were most frequently seen in the phloem crystalliferous parenchyma (from 3 to $21 \mathrm{dpi}$ in ZG14 and from 7 to $14 \mathrm{dpi}$ in both clones, Figures $\mathbf{4 H}, \mathbf{P}$ ). However, the presence of hyphae in heavily pigmented or darkly stained phloem elements cannot be excluded. At $7 \mathrm{dpi}$, hyphae were also seen in tanniniferous phloem parenchyma, axial phloem parenchyma, and occasionally in peridermal stone cells. This distribution persisted until $14 \mathrm{dpi}$, at which point hyphae were also present in phloem fibers and sclereids. From $21 \mathrm{dpi}$, hyphae became less abundant in all of these cell types, and were rarely observed at the inoculation site by $42 \mathrm{dpi}$. By $21 \mathrm{dpi}$, most ray cells at the inoculation site appeared to have appeared to have died. Hyphae were occasionally observed in phellogen $(3,21,42$ dpi), phloem fibers (14 dpi in ZG14), and cambium (ZG14 7-14 dpi).

In TAG5 and ZG14, hyphae branched toward vascular ray parenchyma cells and occasionally other living cells. In several cases, a hypha would branch several times near ray parenchyma cells, appearing to enter each cell through the cell wall pits (Figures 4D,L). Hyphae also seemed to traverse adjacent vessel elements, fibers and cells via the pits (Figures 4F,G,N,O). The location of fungal hyphae coincided with the appearance of the lesion, suggesting that lesion development corresponds approximately to pathogen spread.

\section{Transcriptome Profiling of C. austroafricana Grown In vitro and In planta}

To investigate the induction of pathogenicity factors in C. austroafricana, transcriptome profiling was performed for the fungus grown in vitro and in planta at $3 \mathrm{dpi}$ (Figure 1). 

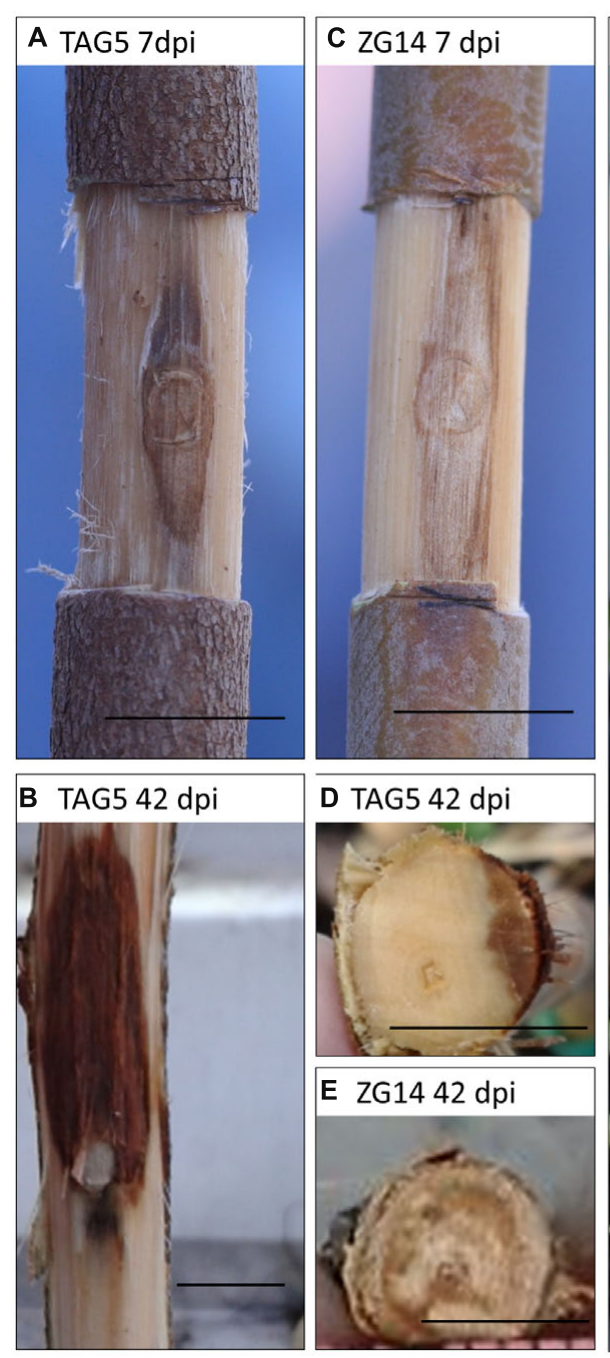
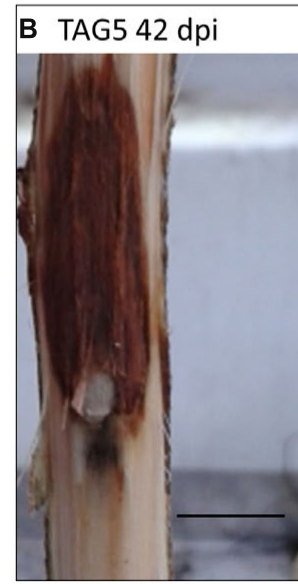

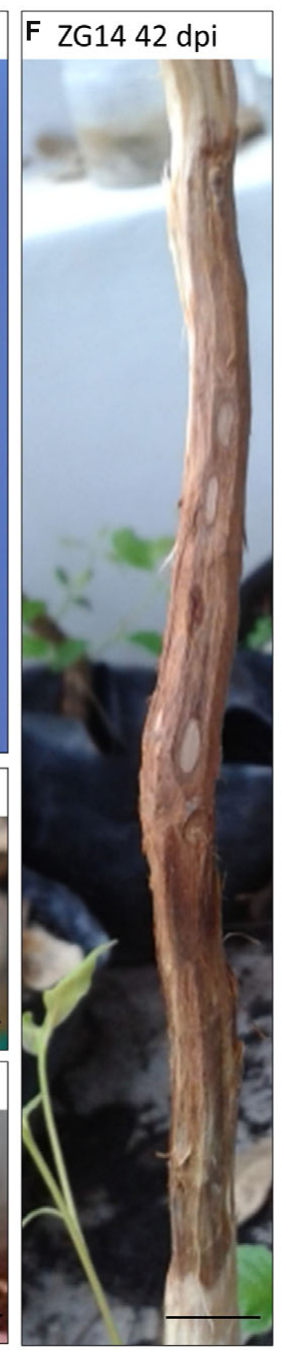

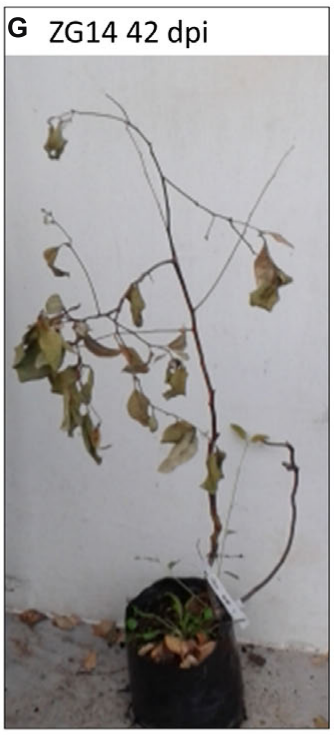

H TAG542 dpi

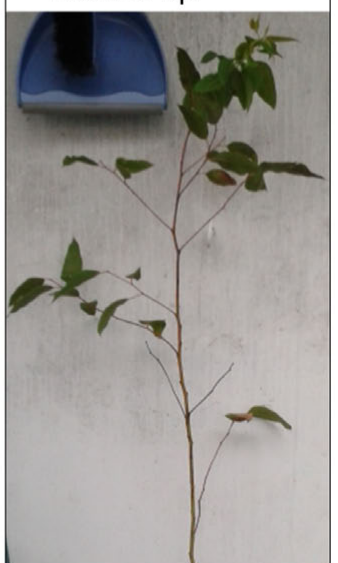

FIGURE 2 | Lesion development in Eucalyptus grandis clones inoculated with C. austroafricana. Lesions in TAG5 (A,B,D) and ZG14 (C,E,F) at 7 dpi and $42 \mathrm{dpi}$ are shown. Different rates of radial lesion development (D,E) were observed, and wilting occurred in some ZG14 plants by 42 dpi, while TAG5 leaves remained healthy $(\mathbf{G}, \mathbf{H})$. Scale bars indicate $10 \mathrm{~mm}$ in all images except $\mathbf{( E )}$, which indicates $5 \mathrm{~mm}$.

Transcriptome profiling of C. austroafricana grown in vitro yielded at least 32 million high-quality paired end reads per biological replicate. Of the 13,205 predicted gene models in the C. austroafricana genome, between 9,289 and 12,572 genes were expressed (FPKM > 0) under the different conditions (Supplementary Table S1). Quartile distributions of the range of FPKM values in vitro and in planta are indicated in Supplementary Table S2. Differential gene expression analysis with Cuffdiff identified 4312 genes that were significantly differentially expressed (DE) in minimal medium compared to complete medium (Supplementary Table S3). Within this list of DE genes, 2313 genes were up-regulated and 1999 genes were down-regulated in minimal medium. Expression analysis of the fungus grown in planta relative to the fungus grown on complete medium, identified 3689 (1774 up-regulated; 1915 down-regulated) and 3353 (1529 up-regulated; 1824 downregulated) DE gene models in ZG14 and TAG5 respectively
(Supplementary Tables S4 and S5). There were 1080 (389 up-regulated; 691 down-regulated) DE gene models expressed in vitro and in planta, while 1552 (718 up-regulated and 834 down-regulated) DE gene models were only expressed in planta. Additionally, 335 genes were only DE expressed in ZG14 (Supplementary Table S6).

\section{Gene-Ontology Enrichment of Differentially Expressed Genes}

In order to identify biological processes that may contribute to pathogenicity, the enrichment of GO terms within each set of $\mathrm{DE}$ genes identified in vitro and in planta was investigated using Blast2GO. Terms from the biological process category that were unique to genes expressed in planta included "cell wall organization or biogenesis," "cellular developmental process," "reproduction," "anatomical structure formation involved in 


\begin{tabular}{|c|c|c|c|c|c|c|c|c|c|c|c|}
\hline & & $3 c$ & lpi & 7 & & 14 & & 21 & & 42 & \\
\hline & Cell type/structure & TAG5 & ZG14 & TAG5 & ZG14 & TAG5 & ZG14 & TAG5 & ZG14 & TAG5 & ZG14 \\
\hline \multirow{5}{*}{$\begin{array}{l}\frac{\xi}{2} \\
\frac{0}{0} \\
\frac{0}{0} \\
0\end{array}$} & Epidermis & & & & & & & & & & \\
\hline & Cork cells & & & & & & & & & & \\
\hline & Stone cells & & & & & & & & & & \\
\hline & Phellogen/Phelloderm & & & & & & & & & & \\
\hline & Oil cavities & & & & & & & & & & \\
\hline \multirow{7}{*}{$\begin{array}{l}\frac{\varepsilon}{\Phi} \\
\frac{\delta}{\frac{c}{\alpha}}\end{array}$} & Phloem rays & & & & & & & & & & \\
\hline & Crystalliferous/axial parenchyma & & & & & & & & & & \\
\hline & Tanniniferous parenchyma & & & & & & & & & & \\
\hline & Sieve tubes & & & & & & & & & & \\
\hline & Companion cells & & & & & & & & & & \\
\hline & Phloem fibres & & & & & & & & & & \\
\hline & Sclereids & & & & & & & & & & \\
\hline$u$ & Ray/fusiform initials & & & & & & & & & & \\
\hline \multirow{4}{*}{$\frac{\varepsilon}{d \vec{d}}$} & Xylem rays & & & & & & & & & & \\
\hline & Xylem vessels & & & & & & & & & & \\
\hline & Vasicentric tracheids/Axial parenchyma & & & & & & & & & & \\
\hline & Xylem fibres & & & & & & & & & & \\
\hline
\end{tabular}

FIGURE 3 | A summary of the location of C. austroafricana within highly susceptible and moderately resistant $\boldsymbol{E}$. grandis clones at the inoculation site using safranin/fast green or lactophenol blue staining. C: cambium; dpi: days post-inoculation. Gray boxes indicate the presence of hyphae.

morphogenesis," and "signal transduction." Biological process terms unique to genes expressed in minimal medium included "cellular amino acid metabolic process" and "sulfur compound metabolic process." Interestingly, some terms within the biological process category such as "carbohydrate metabolic process," "catabolic process," and "generation of precursor metabolites and energy" were under-represented in vitro but over-represented in planta (Figure 5A).

In the molecular function category, the terms "hydrolase activity, acting on glycosyl bonds" and "peptidase activity" were over-represented in planta but under-represented in vitro (Figure 5B). Terms in the molecular function category that were unique to genes expressed under in planta conditions included "enzyme binding," "lipid binding," and "methyltransferase activity." Molecular function terms unique to genes expressed in vitro included "ion binding" and "ligase activity." For the cellular component category, more terms were found among the genes expressed in vitro compared to in planta. All the terms for the genes expressed in vitro were under-represented in the cellular component category. In this category, only one term, "extracellular region," was over-represented and originated from the genes expressed in planta (Supplementary Figure S1).

\section{Identification of Genes Involved in Carbohydrate Metabolism}

Due to the over-representation of the "carbohydrate metabolic process" term among the genes expressed in planta, the C. austroafricana genome was further examined for genes involved in carbohydrate metabolism. A total of 1525 candidates with homologous hits to known genes in the CAZyme database were identified. Among the fungal genes DE in planta, 465 candidates were expressed in TAG5, 525 in ZG14 and 554 in vitro. However, since all of the CAZyme database genes are not necessarily involved in pathogenicity, candidates specifically involved in cell wall hydrolysis and degradation were identified among the DE genes (Table 1). The list included xylanases, endoglucanases, polygalacturonases, cellulases, cellobiohydrolases, pectate lyases, and pectin methylesterases (PMEs). All of the genes involved in cell wall hydrolysis and/or degradation were either absent in fungus grown on MM or expressed at lower levels than in planta.

\section{The Pathogen-Host Interaction (PHI) Database and Pathogenicity Genes}

Since cell wall degradation is unlikely to be the only pathogenicity mechanism employed by $C$. austroafricana, we searched for additional candidates with known involvement in pathogenicity in the DE gene sets using a BLASTP analysis with the PHI database. A total of $1090 \mathrm{DE}$ pathogenicity-related genes were identified among genes DE in ZG14, 971 genes in TAG5 and 1239 in vitro. The PHI database has a number of categories based on the phenotype of the mutants for genes involved in pathogenicity. We focused primarily on genes within the following categories: effectors, loss of pathogenicity and reduced virulence.

\section{Effectors}

This study identified 13 candidates that were homologous to known effectors in the PHI database (Table 2; Supplementary Table S7). Homologs included genes encoding an Ace1, PemG1 and a protein containing a cerato-platanin domain from Magnaporthe grisea, as well as a HopI1 from Pseudomonas syringae. Six C. austroafricana homologs to ACE1 and one to a cerato-platanin MgSM1 from M. grisea, as well as five homologs 

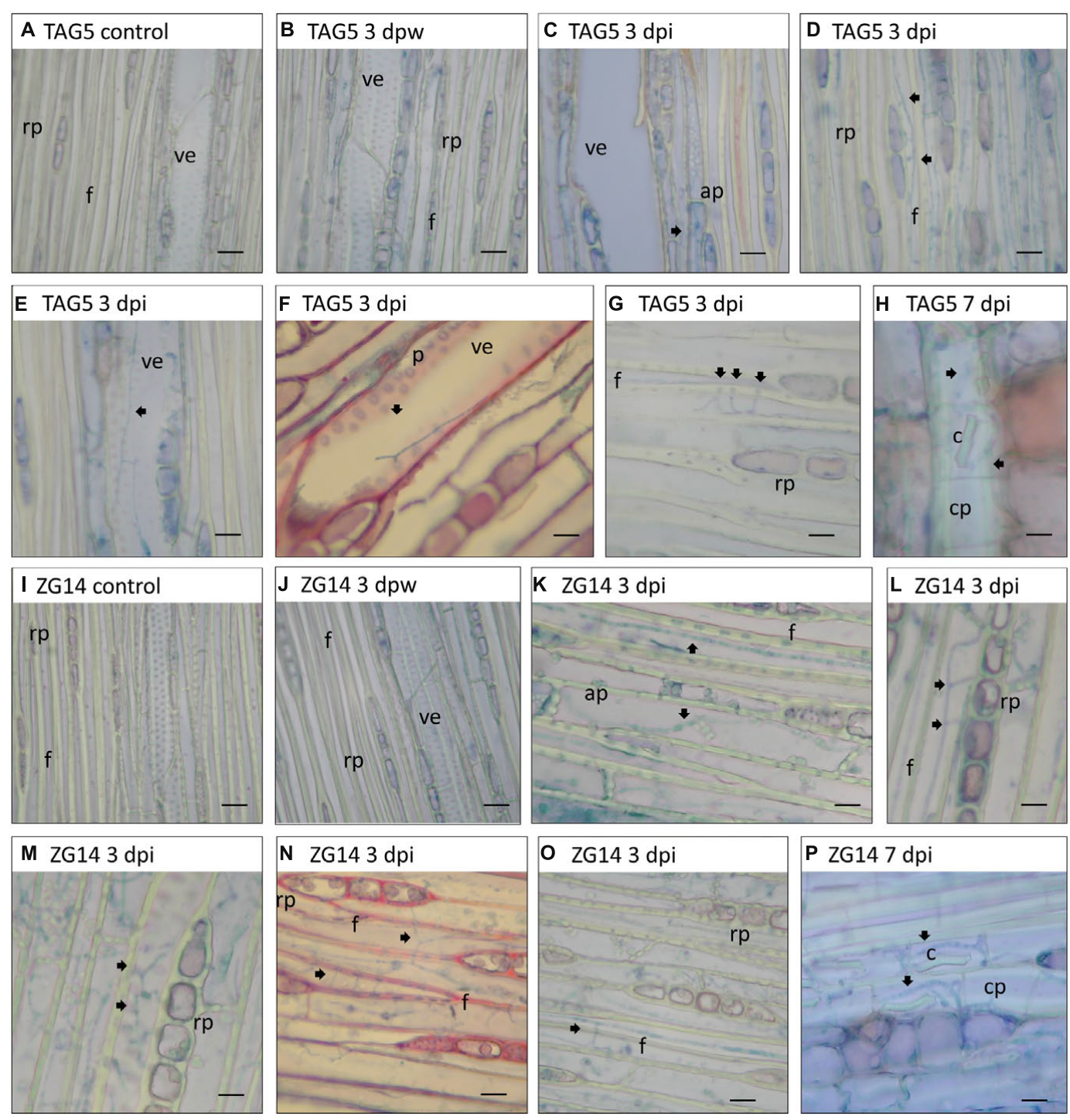

FIGURE 4 | Light micrographs of the most frequent sites where C. austroafricana was observed within inoculated TAG5 and ZG14 plants. All sections were stained with lactophenol blue except (F,N), which were stained with safranin/fast green. (A-H) TAG5. (I-P) ZG14. Arrows indicate hyphae. dpw: days post-wounding; dpi: days post-inoculation; rp: xylem ray parenchyma; f: xylem fiber; ve: xylem vessel element; ap: axial xylem parenchyma; $p$ : cell wall pits; $\mathrm{cp}$ : phloem crystalliferous parenchyma; c: crystal. Scale bars: $10 \mu \mathrm{m}$.

to HopI1 from P. syringae were identified. Included in the list of genes homologous to the Acel effectors were non-ribosomal peptide synthetases (nrps). One of these genes (g2672) with homology to an nrps-like enzyme was only expressed in ZG14 and TAG5 and not in vitro. A HopI1 homolog, g3525, was expressed only in ZG14. Other effectors expressed specifically in ZG14 are shown in Table 2.

\section{Loss of Pathogenicity}

A total of 96 DE fungal genes in ZG14, 83 in TAG5 and 75 in vitro were homologous to genes in the "loss of pathogenicity" category in the PHI database. Mutants of these candidates in the PHI database had an apathogenic phenotype.
A set of $31 \mathrm{DE}$ genes was common to all conditions (Figure 6A; Table 2; Supplementary Table S7). One of the candidates that was expressed at approximately the same level in all conditions was g8986 (developmental regulator flba protein), a homolog of Cryphonectria parasitica regulator of G-protein signaling (CPRGS-1). Several homologs of membrane transporter genes from the ATP-binding cassette $(\mathrm{ABC})$ and major facilitator superfamily (MFS) were DE in vitro and in planta, but with a larger fold change in the latter. These genes are associated with various cellular and metabolic functions and have been implicated in pathogenicity through the secretion of toxins. A candidate homologous to $A B C 3$ in the PHI database, g8540 (leptomycin $b$ resistance protein), was upregulated in vitro and in planta. In this study, g8540 was 

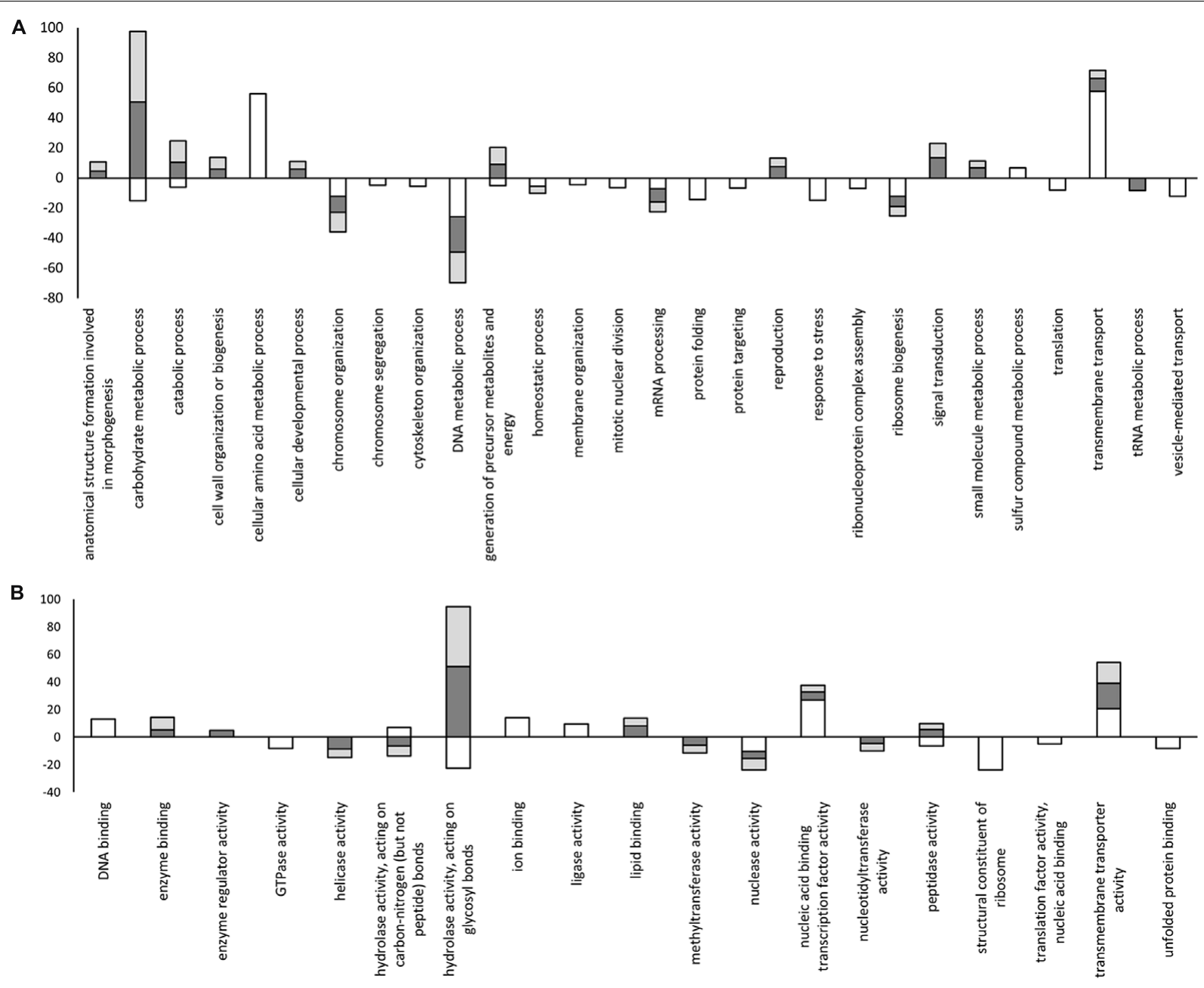

FIGURE 5 | Statistically enriched GO terms identified in the differentially expressed gene lists within the biological process and molecular function category. (A) Biological process; (B) Molecular function. Positive values indicate over-represented terms and negative values indicate under-represented terms. White: minimal medium; Dark gray: ZG14; Light gray: TAG5. The y-axis represents the - $\log _{2}(p$-value) obtained with the Fisher's exact test in Blast2GO. The $\mathrm{x}$-axis $=\mathrm{GO}$ terms

expressed at higher levels in planta ( $\sim 3$-fold up-regulated) than in vitro $(\sim 1.8$ fold up-regulated). Among the genes that were down-regulated in vitro and up-regulated in planta were homologs of NOX2 (g7806, nadph oxidase isoform 2 protein), RHO1 (g11833, rho) and COT1 (g11791, serine threonine-protein kinase cot-1 protein).

Forty-five candidates with homology to the "loss of pathogenicity" category in the PHI database were only expressed in planta (Figure 6A). Among these candidates were an $n$ rps gene (g10597, non-ribosomal peptide) homologous to AMT1 in the PHI database, and a homolog of transcription regulator FOW2 [g7327, $\mathrm{Zn}(\mathrm{II}) 2 \mathrm{cys} 6$ transcription factor], which is involved in mediating plant infection in Fusarium oxysporum. This set included multiple genes involved in the mitogen activated protein kinase (MAPK) and cAMP signaling cascades. The MAPK cascade is involved in diverse cellular functions. Our candidates included the backbone of this signaling cascade Ste11 (MAPKKK), the adaptor protein Ste50, Ste7 (MAPKK),
Fus3/Kss1 (MAPK), upstream candidates (Ste20 and Cla4) and downstream candidates (Ste12). Ste12 controls MAPK responses pertaining specifically to invasive growth and pathogenicity. Induction of the MAPK cascade affecting pathogenicity is initiated by a small GTPase, Racl. All of these MAPK signaling cascade candidates were up-regulated only in planta (Table 2; Supplementary Table S7). The expression of RAS2 (g12863, ras small monomeric gtpase), which acts upstream of Ste20, was DE only in ZG14 (Table 2; Supplementary Table S7). Furthermore, the cAMP cascade involves three main components: heteromeric G-proteins, adenylate cyclase (AC) and cAMP-dependent protein kinase (CPK). CPK (g10089, camp-dependent protein kinase catalytic subunit) was DE in both TAG5 and ZG14.

\section{Reduced Virulence}

In addition to the "loss of pathogenicity" category, 385 genes homologous to candidates associated with a reduced virulence phenotype were identified in ZG14, 355 in TAG5 and 407 
TABLE 1 | Differentially expressed genes in Chrysoporthe austroafricana putatively involved in cell wall hydrolysis.

\begin{tabular}{|c|c|c|c|c|c|c|}
\hline Gene ID ${ }^{a}$ & Sequence description & CAZyme ID & CAZyme description & $\mathrm{ZG} 14^{\mathrm{b}}$ & TAG5 $^{\text {b }}$ & $\mathbf{M M}^{\mathrm{b}}$ \\
\hline g11257 & Cellobiohydrolase ii protein & $\mathrm{GH} 6 \mid \mathrm{CBM} 1$ & Cellobiohydrolase & 6.66 & 5.48 & - \\
\hline$g 1627$ & Cellobiohydrolase ii & GH6| CBM1 & Cellobiohydrolase & 5.06 & 4.08 & -3.36 \\
\hline g5329 & Glycoside hydrolase family 5 protein & GH5 & Cellulase & 5.07 & 4.22 & 1.17 \\
\hline g4314 & Endoglucanase 3 precursor & $\mathrm{GH} 5$ & Cellulase & 4.16 & 3.46 & -0.98 \\
\hline g6568 & Glycoside hydrolase family 5 protein & $\mathrm{GH} 5$ & Cellulase & 4.11 & 3.05 & -2.64 \\
\hline g7427 & Glycoside hydrolase family 5 protein & GH5 & Cellulase & 4.84 & 4.85 & -1.37 \\
\hline g8109 & Endo-n-acetyl-beta-d-glucosaminidase precursor & $\mathrm{GH} 18$ & Chitinase & 3.67 & 3.35 & 0.86 \\
\hline g4000 & Class iii chitinase 2 protein & GH18| CBM1 & Chitinase & 2.76 & 3.17 & 2.90 \\
\hline g1953 & Endochitinase 1 precursor & $\mathrm{GH} 18$ & Chitinase & 1.01 & 1.47 & - \\
\hline g1810 & Endo- -beta-xylanase precursor & $\mathrm{GH} 10 \mathrm{O} \mathrm{CBM} 1$ & Endo-1,4- $\beta$-xylanase & 6.26 & 5.42 & - \\
\hline g5394 & Glycoside hydrolase family 10 protein & $\mathrm{GH} 10$ & Endo-1,4- $\beta$-xylanase & 5.19 & 4.93 & - \\
\hline g5445 & Xyloglucan-specific endo-beta- -glucanase a & $\mathrm{GH} 12$ & Endoglucanase & 5.86 & 6.07 & - \\
\hline g3498 & Xyloglucan-specific endo-beta- -glucanase precursor & $\mathrm{GH} 12$ & Endoglucanase & 3.21 & 3.12 & -1.17 \\
\hline g1022 & Arabinogalactan endo- -beta-galactosidase & GH53 & Endo- $\beta-1,4$-galactanase & 5.00 & 5.35 & 0.92 \\
\hline g11198 & Glycoside hydrolase family 7 protein & $\mathrm{GH} 7$ & Endo- $\beta$-1,4-glucanase & 7.46 & 6.82 & 0.91 \\
\hline g15 & Cellobiohydrolase precursor & $\mathrm{GH} 7$ & Endo- $\beta$-1,4-glucanase & 7.12 & 7.05 & - \\
\hline g8111 & Endoglucanase i & $\mathrm{GH} 7$ & Endo- $\beta$-1,4-glucanase & 3.27 & 1.94 & -5.20 \\
\hline$g 1213$ & Achain pectin lyase a & PL1 & Pectate lyase & 2.34 & 2.51 & - \\
\hline$g 1125$ & Carbohydrate esterase family 8 protein & CE8 & Pectin methylesterase & 4.90 & 5.01 & 0.72 \\
\hline g11009 & Pectinesterase precursor & CE8 & Pectin methylesterase & 3.29 & 3.46 & -1.45 \\
\hline g9733 & Glycoside hydrolase family 28 protein & $\mathrm{GH} 28$ & Polygalacturonase & 8.54 & 8.40 & 1.50 \\
\hline g3288 & Endopolygalacturonase 1 & $\mathrm{GH} 28$ & Polygalacturonase & 7.83 & 7.07 & - \\
\hline g2415 & Glycoside hydrolase family 28 protein & $\mathrm{GH} 28$ & Polygalacturonase & 6.64 & 6.37 & - \\
\hline g12766 & Rhamnogalacturonase a & $\mathrm{GH} 28$ & Polygalacturonase & 6.00 & 5.94 & - \\
\hline$g 1777$ & Exopolygalacturonase protein & $\mathrm{GH} 28$ & Polygalacturonase & 3.94 & 3.91 & - \\
\hline$g 4274$ & Pectin lyase-like protein & $\mathrm{GH} 28$ & Polygalacturonase & 2.97 & 3.68 & - \\
\hline g587 & Galacturan -alpha-galacturonidase c & $\mathrm{GH} 28$ & Polygalacturonase & 2.05 & 2.23 & - \\
\hline g2053 & Polygalacturonase 5 & $\mathrm{GH} 28$ & Polygalacturonase & 1.30 & 1.45 & -2.68 \\
\hline g3432 & Endopolygalacturonase partial & $\mathrm{GH} 28$ & Polygalacturonase & 6.06 & 6.20 & -1.59 \\
\hline g7776 & Beta-glucosidase g & $\mathrm{GH} 3$ & $\beta$-glucosidase & 8.34 & 8.35 & - \\
\hline$g 1439$ & Glycoside hydrolase family 3 protein & $\mathrm{GH} 3$ & $\beta$-glucosidase & 6.02 & 6.04 & - \\
\hline g1799 & Glycoside hydrolase family 3 protein & $\mathrm{GH} 3$ & $\beta$-glucosidase & 3.53 & 3.54 & - \\
\hline g5920 & Glycoside hydrolase family 3 protein & $\mathrm{GH} 3$ & $\beta$-glucosidase & 1.97 & 2.64 & - \\
\hline
\end{tabular}

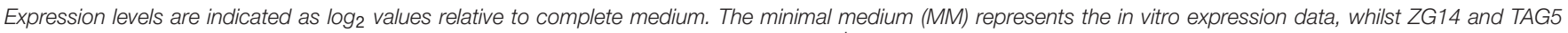

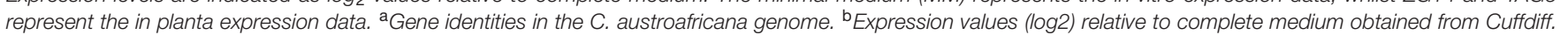
Positive values indicate up-regulation; Negative values indicate down-regulation.

in vitro (Figure 6B; Table 2; Supplementary Table S7). This category includes genes that facilitate enhanced virulence, i.e., mutants have a reduction in virulence, but do not completely lose their pathogenicity. A transmembrane domain containing gene encoding a homolog of mucin (g10997, Msb2), which is involved in initiating the MAPK cascade via Rac1, was found in this category. Expression of a homolog of $M s b 2$ was up-regulated only in planta, as observed with the other MAPK cascade genes. A homolog of the AC (g1759, adenylate cyclase, acy) component of the cAMP signaling pathway was also in this category and only up-regulated in ZG14. Several genes involved in cell wall hydrolysis were identified in these lists, including homologs of pectinesterase, endo-beta xylanase, polygalacturonase and glucan beta-glucosidase. A Snf1 homolog (g12947, protein kinase snf1 protein) was expressed at lower levels in vitro $(\sim 0.6$ fold up-regulated) than in planta ( $\sim 3.6$ fold up-regulated) and is associated with the regulation of CWDEs.
Other candidates with homologs in this category included isocitrate lyase (ICL1), which is involved in the glyoxylate cycle, a glutathione peroxidase (MoHYR1) involved in ROS detoxification, polyketide synthases (PKSs) involved in toxin production, and numerous MFS and ABC transporters (Table 2; Supplementary Table S7). In C. austroafricana, ICL (g12102, isocitrate lyase) was DE only in planta. An additional ICL homolog (g10370, isocitrate lyase) was DE only in ZG14. The HYR1 gene (g12951) was DE only in planta, with a larger fold change in the susceptible host. PKS genes of C. austroafricana (g11676 and g7022) were DE only in ZG14, but only g7022 was associated with reduced virulence.

Genes associated with the manipulation of phytohormone signaling, particularly salicylic acid and gibberellins, were also present in the "reduced virulence" category (Table 2; Supplementary Table S7). In C. austroafricana, two salicylate hydroxylase genes (g3443 and g6514) associated with reduced 
TABLE 2 | Putative pathogenicity genes of Chrysoporthe austroafricana according to the Pathogen-Host Interaction (PHI) database.

\begin{tabular}{|c|c|c|c|c|c|c|}
\hline \multirow[b]{2}{*}{ Gene ID ${ }^{a}$} & \multirow[b]{2}{*}{ Sequence description } & \multicolumn{3}{|c|}{$\log _{2}$ expression } & \multicolumn{2}{|c|}{ PHI Database classification } \\
\hline & & $\mathrm{MM}^{\mathrm{b}}$ & $\mathrm{ZG14} 4^{\mathrm{b}}$ & TAG $^{\text {b }}$ & e-value ${ }^{c}$ & Description $^{d}$ \\
\hline \multicolumn{7}{|l|}{ Effectors } \\
\hline g11706 & Hypothetical protein & - & -0.90 & -0.75 & $2.83 \mathrm{E}-10$ & 2216_PemG1_Effector \\
\hline g2672 & nrps-like enzyme & - & 2.57 & 2.86 & $1.64 \mathrm{E}-11$ & 325_ACE1_Effector \\
\hline g345 & Methyltransferase type 11 protein & -0.95 & - & - & $1.58 \mathrm{E}-06$ & 325_ACE1_Effector \\
\hline g3525 & er associated chaperone protein & - & 0.83 & - & 4.04E-08 & 981_hopl1_Effector \\
\hline g353 & Domain-containing protein & 0.95 & - & - & $1.79 \mathrm{E}-10$ & 981_hopl1_Effector \\
\hline g3586 & Non-ribosomal peptide synthetase & 6.47 & 4.01 & - & $2.97 \mathrm{E}-13$ & 325_ACE1_Effector \\
\hline g3592 & Chaperone dnaj 2 & - & 0.87 & - & 4.29E-08 & 981_hopl1_Effector \\
\hline g6093 & Cerato-platanin-domain-containing protein & -2.31 & -0.70 & -0.53 & 8.79E-35 & 2118_MgSM1_Effector \\
\hline g6178 & Sterol 24-c-methyltransferase & -1.29 & -1.91 & -2.30 & 8.07E-06 & 325_ACE1_Effector \\
\hline g6409 & $\mathrm{N} / \mathrm{A}$ & - & 8.83 & - & 0 & 325_ACE1_Effector \\
\hline g7591 & $\begin{array}{l}\text { Small glutamine-rich tetratricopeptide } \\
\text { repeat-containing protein a protein }\end{array}$ & - & 0.96 & - & $1.85 E-14$ & 981_hopl1_Effector \\
\hline g8165 & Domain-containing protein & - & -1.43 & -1.79 & 2.46E-09 & 981_hopl1_Effector \\
\hline g8582 & Domain-containing protein & 0.81 & - & - & 8.03E-06 & 981_hopl1_Effector \\
\hline g8610 & $\mathrm{N} / \mathrm{A}$ & - & 9.54 & 7.66 & 0 & 325_ACE1_Effector \\
\hline \multicolumn{7}{|c|}{ Loss of pathogenicity } \\
\hline g8986 & Developmental regulator flba protein & 1.83 & 2.04 & 1.88 & 0 & 343_CPRGS1_Loss of pathogenicity \\
\hline g8540 & Leptomycin b resistance protein pmd1 protein & 1.80 & 3.68 & 3.26 & 0 & 2042_ABC3_Loss of pathogenicity \\
\hline g7806 & nadph oxidase isoform 2 protein & -1.06 & 1.61 & 1.22 & 0 & 859_NOX2_Loss of pathogenicity \\
\hline g11833 & rho other & -0.65 & 2.01 & 2.06 & $4.57 \mathrm{E}-58$ & 270_RHO1_Loss of pathogenicity \\
\hline g11791 & Serine threonine-protein kinase cot-1 protein & -0.82 & 1.50 & 1.50 & 0 & 393_CpCOT1_Loss of pathogenicity \\
\hline g10597 & Non-ribosomal peptide & - & 6.63 & 6.30 & 0 & 160_AMT_Loss of pathogenicity \\
\hline g7327 & zn 2cys6 transcription factor & - & 1.96 & 2.06 & 0 & 734_FOW2_Loss of pathogenicity \\
\hline g7897 & ste ste11 protein kinase protein & - & 1.32 & 1.62 & 0 & 2119_MST11p_Loss of pathogenicity \\
\hline g1638 & Dual specificity protein kinase fuz7 & - & 0.84 & 0.98 & 0 & 417_MST7_Loss of pathogenicity \\
\hline g10027 & Protein kinase regulator ste50 & - & 1.25 & 1.27 & 0 & 2121_MST50p_Loss of pathogenicity \\
\hline g5932 & Mitogen-activated protein kinase & - & 0.83 & 0.52 & 0 & 170_CMK1_Loss of pathogenicity \\
\hline g5559 & ph domain-containing protein & - & 1.30 & 1.14 & 2.59E-05 & 528_CLA4_Loss of pathogenicity \\
\hline$g 173$ & ste like transcription factor & - & 1.35 & 1.13 & 0 & 2187_MST12_Loss of pathogenicity \\
\hline g2836 & rho gtpase & - & 0.77 & 0.77 & $3.43 E-87$ & 2054_Rac1_Loss of pathogenicity \\
\hline g12863 & ras small monomeric gtpase & - & 0.50 & - & $1.02 \mathrm{E}-69$ & 269_RAS2_Loss of pathogenicity \\
\hline g10089 & $\begin{array}{l}\text { CAMP-dependent protein kinase catalytic } \\
\text { subunit }\end{array}$ & - & 1.17 & 1.24 & 4.8E-160 & 341_CPK1_Loss of pathogenicity \\
\hline \multicolumn{7}{|c|}{ Reduced virulence } \\
\hline g10997 & Mucin family signaling protein & - & 1.41 & 0.86 & $9.19 \mathrm{E}-21$ & 2284_Msb2_Reduced virulence \\
\hline g1759 & Adenylate acy & - & 1.57 & - & 0 & 81_MAC1_Reduced virulence \\
\hline g12947 & Protein kinase snf1 protein & 0.68 & 3.61 & 3.60 & 0 & 1197_Snf1_Reduced virulence \\
\hline g12102 & Isocitrate lyase & - & 1.37 & 1.56 & 8.5E-135 & 261_ICL1_Reduced virulence \\
\hline g10370 & Isocitrate lyase & - & 0.93 & - & 0 & 305_ICL1_Reduced virulence \\
\hline g12951 & Glutathione peroxidase & - & 1.51 & 1.08 & $1.07 \mathrm{E}-70$ & 2356_MoHYR1_Reduced virulence \\
\hline g7022 & Polyketide synthase & - & 2.48 & - & 0 & 55_PKS1_Reduced virulence \\
\hline g3443 & Salicylate hydroxylase & - & - & 2.94 & 9.99E-73 & 112_MAK1_Reduced virulence \\
\hline g6514 & Salicylate hydroxylase & - & - & 0.94 & $1.79 \mathrm{E}-63$ & 112_MAK1_Reduced virulence \\
\hline g5746 & Ent-kaurene oxidase protein & - & 4.28 & - & $2.21 \mathrm{E}-12$ & 553_ssrA_Reduced virulence \\
\hline
\end{tabular}

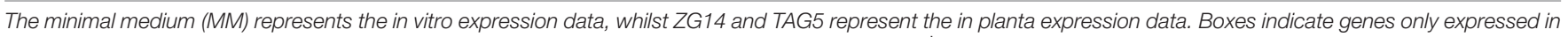

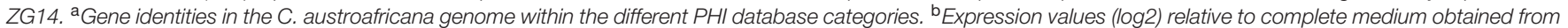

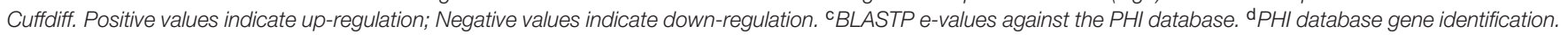

virulence were expressed only in TAG5. An additional putative salicylate hydroxylase gene (g11021) was up-regulated with a larger fold change in planta ( $\sim 3$ fold up-regulated) than in vitro ( $\sim 0.7$ fold up-regulated), but this gene was associated with an "unaffected pathogenicity" phenotype. A C. austroafricana entkaurene oxidase gene (g6592, ent-kaurene oxidase) was DE in TAG5 and ZG14, while another (g5746, ent-kaurene oxidase protein) was only expressed in ZG14. The homolog of the gene 

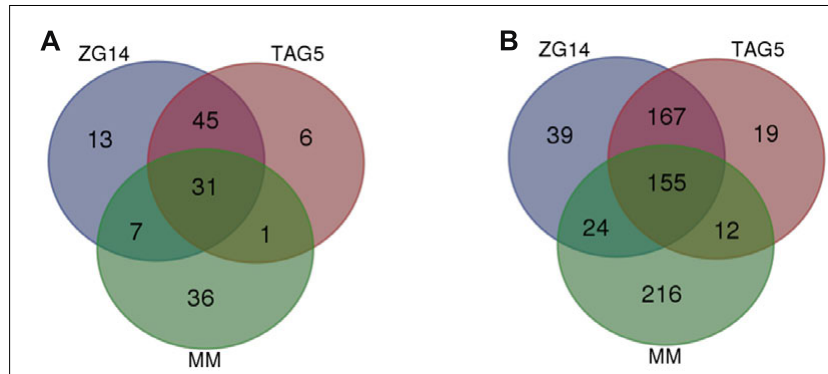

FIGURE 6 | Number of differentially expressed genes identified in the loss of pathogenicity and reduced virulence $\mathrm{PHI}$ categories in

E. grandis clones TAG5 and ZG14. (A) Loss of pathogenicity; (B) reduced virulence. MM, minimal medium.

expressed only in ZG14 was associated with a reduced virulence phenotype in the PHI database.

\section{RT-qPCR Validation of Transcriptome Data}

Selected candidates from among the genes DE in minimal medium, TAG5, and ZG14 were used to validate the transcriptome profiling with reverse transcription quantitative polymerase chain reaction (RT-qPCR). The following genes were chosen for validation of expression in vitro (complete medium vs. minimal medium) well as in planta (complete medium vs. ZG14; complete medium vs. TAG5): g4000 (class iii chitinase 2 protein), g3586 (non-ribosomal peptide synthetase), g28 (polyamine transporter 2 protein), and g1910 ( $m f s$ transporter). In addition, g7696 (monocarboxylate permease-like protein) was selected for validation of genes expressed in vitro. The following genes were also selected for the validation of genes expressed in planta: g5867 (acetolactate synthase protein); g8441 (auxin-induced protein); g2053 (polygalacturonase 5) and g11257 (cellobiohydrolase ii protein). All the genes, except g1910, matched their corresponding transcriptome profiles (Figure 7).

\section{DISCUSSION}

The pathogen C. austroafricana naturally infects E. grandis through wounds in the stem, but this infection mechanism can be mimicked under controlled conditions in order to study the interaction. In our study, this established pathosystem was employed to understand how the pathogen spreads through the host and to identify which pathogenicity factors are activated by C. austroafricana in order to propose mechanisms by which it can cause disease.

\section{The Physical Interaction between C. austroafricana and E. grandis}

Tissue of moderately resistant and highly susceptible E. grandis clones infected with $C$. austroafricana was subjected to histochemical analysis in order to visualize the physical interaction of this pathogen with its host. The pathogen was observed in the same cell types and structures in both clones. This suggests that it follows the same route of spread in these
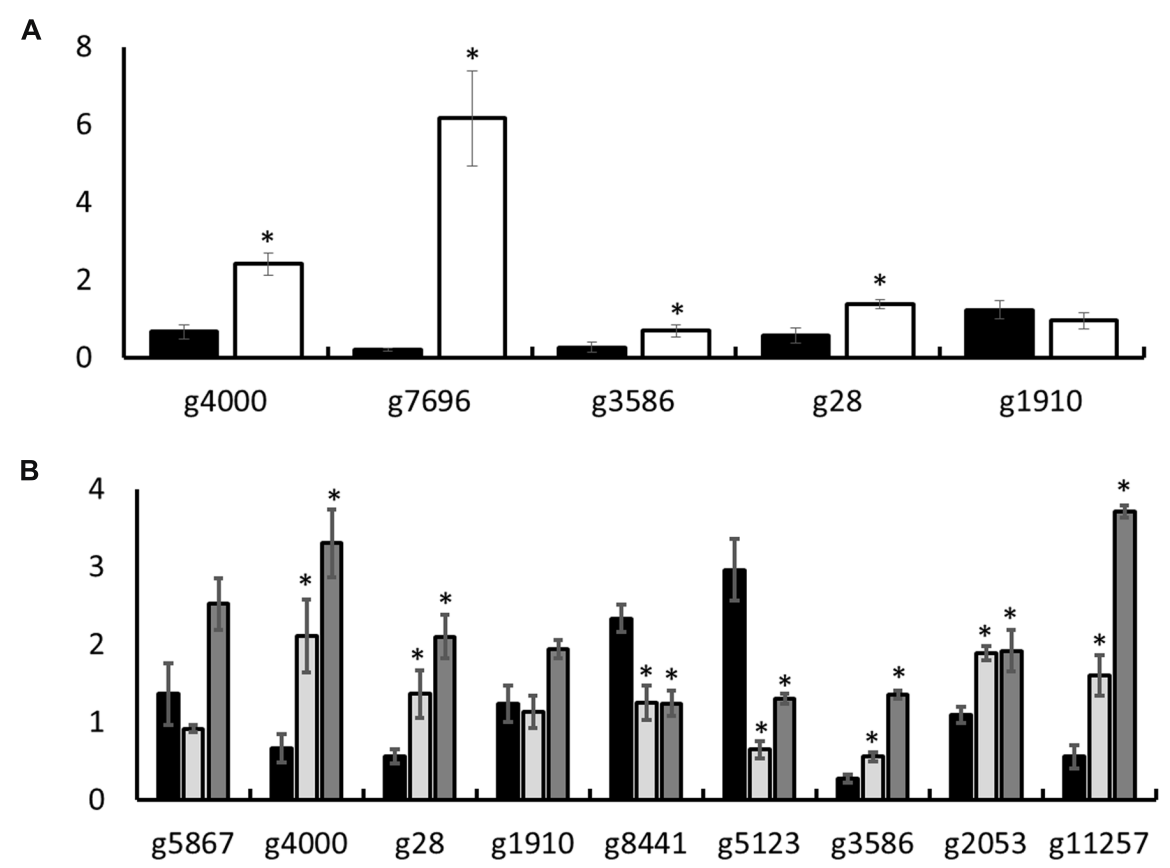

FIGURE 7 | Reverse transcription quantitative polymerase chain reaction (RT-qPCR) validation of transcriptome profiling in vitro and in planta. (A) In vitro; (B) in planta. The $y$-axis indicates the expression level. Black bars represent complete medium. (A) The white bars represent minimal medium. (B) The light gray bars represent TAG5 and the dark gray bars represent ZG14. Significance relative to complete medium is indicated by (Student's $t$-test, two-tailed, * $p$-value < 0.05 ). 
clones. This route may simply be that which presents the least resistance to movement. For example, wood-rotting fungi typically spread faster axially, since most large elements are orientated in this direction (Pearce, 1996). In this study, hyphae were most frequently seen in non-living elements such fibers and xylem vessels. These elements would enable axial spread; fiber lumina are long, while xylem vessels form continuous channels of relatively large diameter through which hyphae can spread with ease. Radial spread could be facilitated by ray parenchyma cells, where hyphae were also observed, and through the walls of vessel elements. Tangential spread would involve movement through the cell wall pits of adjacent elements such as xylem vessels and fibers, and is expected to be most arduous (Pearce, 1996). These rates of spread are consistent with the rate of lesion development and with the tentative observation that lesion formation coincides with the location of hyphae.

In addition, hyphae showed a marked affinity for cell wall pits. Hyphae were observed in direct contact with cell wall pits, which they frequently traversed, and also appeared to enter living parenchyma cells via cell wall pits. The fungus could obtain nutrients from these host cells or manipulate the plant defense response during this direct interaction. The ability to cross cell wall pits may be crucial for C. austroafricana to proliferate in the host. Knowledge about pathogen location and putative mechanism of spread provides a foundation for exploring the molecular mechanisms by which the pathogen proliferates in the host.

\section{Minimal Medium Reveals General Stress Responses Induced in C. austroafricana}

The stress induced by the limited availability of nutrients in MM resulted in responses that could be related to pathogenicity mechanisms. Signal transduction is crucial for the response of eukaryotic cells to extracellular signals. Candidates such as the G-protein CRPGS-1 are expected to be DE in vitro and in planta, and this was observed. In Cryphonectria parasitica, CPRGS-1 has a crucial role in pathogenicity, since loss of function mutants are unable to infect chestnut stems (Lengeler et al., 2000; Segers et al., 2004). In this study, homologs of several genes that allow the pathogen to survive oxidative stress and facilitate the maintenance of fungal cell wall integrity were either downregulated in vitro or more highly induced in planta (Table 2). Numerous studies showed that mutations in these genes result in apathogenicity (Scheffer et al., 2005; Sun et al., 2006; Egan et al., 2007; Martinez-Rocha et al., 2008; Segmüller et al., 2008; Tudzynski et al., 2012; Morita et al., 2013). These results show that the responses in minimal medium can provide an indication of pathogenicity mechanisms, but cannot replace an investigation of the direct interaction in planta.

\section{Pathogenicity Mechanisms of C. austroafricana Elucidated In planta Cell Wall Degradation and Fungal Cell Wall Maintenance}

Investigating the expression of fungal genes in planta enables identification of putative fungal pathogenicity mechanisms induced in the host environment. One of the first events during fungal invasion is the secretion of CWDEs to permeate the host tissue (Kubicek et al., 2014). We identified several putative CWDEs that were up-regulated in planta (Table 1). A key candidate involved in the regulation of CWDEs, Snf1, is an important pathogenicity factor in Magnaporthe oryzae, Fusarium oxysporum, Gibberella zeae, and Cochliobolus carbonum (Tonukari et al., 2000; Ospina-Giraldo et al., 2003; Lee et al., 2009; Yi et al., 2009; Turra et al., 2014). Snf1 was expressed at higher levels in planta than in vitro in the current study (Table 2). These CWDEs could be crucial for the movement of C. austroafricana via cell wall pits, allowing the pathogen to manipulate or penetrate host cells.

\section{Signal Transduction}

In several eukaryotic organisms, signal transduction occurs via the sequential phosphorylation of protein kinases known as MAPKs. Fungal pathogens predominantly employ the Fus3/Kss1 pathway for mediating pathogenesis, and orthologs of candidates in this pathway have been found in several pathogenic fungi (Zhao et al., 2007). In this study, the ortholog of Fus3/Kss1 (g5932, mitogen-activated protein kinase) was identified as CMK1 (Takano et al., 2000). RAS2 was DE in ZG14 (Table 2). Deletion of RAS2 in F. graminearum decreased phosphorylation in the Fus3/Kss1 pathway, compromising virulence (Bluhm et al., 2007; Turra et al., 2014). AC is also expressed only in ZG14. Candidates of the cAMP signaling cascade, $C P K$ and $A C$, have been associated with pathogenicity in various phytopathogen interactions (Choi and Dean, 1997; Klimpel et al., 2002; Yamauchi et al., 2004; Wayne and Rollins, 2007; Garcia-Martinez et al., 2012; Bormann et al., 2014).

\section{Fungal Effectors and Toxin Production}

Upon infiltration, the fungus needs to contend with the defense mechanisms induced by the host. For successful colonization, the fungus requires various pathogenicity mechanisms such as the secretion of effector molecules (Stergiopoulos and de Wit, 2009; Wang et al., 2014). Some effector proteins, the NRPSs, exert their role in pathogenicity by producing fungal toxins (Oide et al., 2006; Chen et al., 2013; Bills et al., 2014). In this study, we identified two NRPS candidates (Table 2). PKSs are also associated with the biosynthesis of toxins in Cochliobolus heterostrophus, Cercospora nicotianae, Botrytis Cinerea, and Gibberella fujikuroi (Yang et al., 1998; Proctor et al., 1999; Choquer et al., 2005; Dalmais et al., 2011). In this study, the expression of two PKS genes only in the susceptible host environment may contribute to the proliferation of C. austroafricana.

\section{Combating Host Responses and Nutrient Assimilation}

Phytohormone signaling cascades are important for several defense mechanisms that can lead to slower spread of the pathogen. These pathways can be manipulated by pathogens to facilitate their own growth and proliferation. Fungi can produce hormones to perturb the phytohormone balance within the host to facilitate susceptibility (Mobius and Hertweck, 2009). 
One of the first committed intermediates for GA biosynthesis is ent-kaurene, which is oxidized to ent-kaurenol by ent-kaurene oxidase (Tudzynski, 2005). Ent-kaurene is a common intermediate in GA biosynthesis of plants and fungi (Hedden et al., 2002). In Xanthomonas oryzae, ent-kaurene oxidase acts as a virulence factor by manipulating the interplay between GA and JA in rice (Lu et al., 2015). In TAG5, GA levels were reduced at 3 dpi whilst this reduction was only observed in the susceptible host at $7 \mathrm{dpi}$ (Mangwanda et al., 2015). This may be due to the expression of an ent-kaurene oxidase candidate in the susceptible ZG14 at 3dpi (Table 2). Furthermore, salicylate hydroxylase is an SA-degrading enzyme that converts SA to catechol and can serve as a virulence factor in pathogens that require lower levels of SA to proliferate within maize plants (Penn and Daniel, 2013; Rabe et al., 2013). We previously showed that TAG5 has higher basal levels of SA than ZG14 (Mangwanda et al., 2015) and that the pre-treatment of ZG14 with SA increases its level of resistance to that of TAG5 (Naidoo et al., 2013). Therefore, the expression of putative salicylate hydroxylases in TAG5 (Table 2) is another possible mechanism by which the pathogen manipulates the host defense response. Such potential interactions, i.e., ent-kaurene oxidase modulating GA and SA hydroxylase modulating SA, have been described in herbaceous systems. Our findings support the notion that these parallel mechanisms exist in the interaction of pathogens with herbaceous and woody plants.

Phytopathogens invade host cells to obtain nutrients which aid in establishing infection. One of the strategies that fungi employ to achieve this is through the glyoxylate pathway, which contains the key enzyme ICL. This enzyme contributes to pathogenicity in pathogens such as Leptosphaeria maculans, Colletotrichum lagenarium, and M. grisea (Idnurm and Howlett, 2002; Wang et al., 2003; Asakura et al., 2006; Dunn et al., 2009). In the current study, we observed the expression of ICL in planta and not in vitro, suggesting a role for the glyoxylate pathway in C. austroafricana virulence.

\section{CONCLUSION}

We have identified possible mechanisms and candidate genes associated with fungal spread and pathogenicity of C. austroafricana in E. grandis. While the PHI database contains data from functionally characterized plant pathogen interactions, pending functional characterization, the roles of the genes in the $C$. austroafricana interactions are speculative. Future work will focus on the putative salicylate hydroxylase and ent-kaurene oxidase genes in C. austroafricana to determine their roles in pathogenicity. This will provide functional evidence of whether these host defense and pathogen strategies are similar in herbaceous and woody pathosystems.

\section{AUTHOR CONTRIBUTIONS}

RM performed the transcriptome experimental work and associated data analysis and interpretation, as well as writing the manuscript. LZ conceived and performed the microscopic investigation and contributed to writing the manuscript. SN conceived the study, obtained funding to support the research, participated in its design, coordination, biological interpretation of the results and helped to write the manuscript. AM, NvdM, LM, and DB provided input into the design and technical aspects, and assisted with critical evaluation of the manuscript. All authors have read and approved the final version of the manuscript.

\section{FUNDING}

The results presented in this study were, or will be, included in the doctoral theses of RM and LZ. This work was supported by the Genomics Research Institute (GRI) at the University of Pretoria; the National Research Foundation's (NRF) Bioinformatics and Functional Genomics Programme (NBFG) (NRF Thuthuka grant ID 87912); the Forest Molecular Genetics Programme by Mondi and Sappi, and the Technology and Human Resources for Industry Programme (THRIP grant number ID 86936), the Department of Science and Technology, The Eucalyptus Genomics Platform: tree genomics and biotechnology for wood fiber, bioenergy and biomaterials. Any opinion, finding and conclusion or recommendation expressed in this material is that of the author(s) and the NRF does not accept any liability in this regard.

\section{ACKNOWLEDGMENTS}

We would like to acknowledge Dr. Veldie van Greuning for his generous assistance with and advice on microscopy, plant anatomy and histochemistry, as well as his critical perusal of the manuscript.

\section{SUPPLEMENTARY MATERIAL}

The Supplementary Material for this article can be found online at: http://journal.frontiersin.org/article/10.3389/fmicb. 2016.01953/full\#supplementary-material

FIGURE S1 | Statistically enriched GO terms identified in the differentially expressed gene lists within the cellular component category. Positive values indicate over-represented terms and negative values indicate under-represented terms. White: minimal medium; Dark gray: ZG14; Light gray: TAG5. The $y$-axis represents the - $\log _{2}(p$-value) obtained with the Fisher's exact test in Blast2GO. The x-axis represents the GO terms. 


\section{REFERENCES}

Asakura, M., Okuno, T., and Takano, Y. (2006). Multiple contributions of peroxisomal metabolic function to fungal pathogenicity in Colletotrichum lagenarium. Appl. Environ. Microbiol. 72, 6345-6354. doi: 10.1128/AEM. 00988-06

Bills, G., Li, Y., Chen, L., Yue, Q., Niu, X. M., and An, Z. (2014). New insights into the echinocandins and other fungal non-ribosomal peptides and peptaibiotics. Nat. Prod. Rep. 31, 1348-1375. doi: 10.1039/C4NP00046C

Blankenberg, D., Von Kuster, G., Coraor, N., Ananda, G., Lazarus, R., Mangan, M., et al. (2010). Galaxy: a web-based genome analysis tool for experimentalists. Curr. Protoc. Mol. Biol. Chapter 19:Unit 19.10.1-19.10.21.

Bluhm, B. H., Zhao, X., Flaherty, J. E., Xu, J.-R., and Dunkle, L. D. (2007). RAS2 regulates growth and pathogenesis in Fusarium graminearum. Mol. Plant Microbe Interact. 20, 627-636. doi: 10.1094/MPMI-20-6-0627

Bormann, J., Boenisch, M. J., Bruckner, E., Firat, D., and Schafer, W. (2014). The adenylyl cyclase plays a regulatory role in the morphogenetic switch from vegetative to pathogenic lifestyle of Fusarium graminearum on wheat. PLoS ONE 9:e91135. doi: 10.1371/journal.pone.0091135

Bruno, V. M., Wang, Z., Marjani, S. L., Euskirchen, G. M., Martin, J., Sherlock, G., et al. (2010). Comprehensive annotation of the transcriptome of the human fungal pathogen Candida albicans using RNA-seq. Genome Res. 20, 1451-1458. doi: $10.1101 /$ gr.109553.110

Chattaway, M. M. (1953). The anatomy of bark. I. The genus Eucalyptus. Aust. J. Bot. 1, 402-433. doi: 10.1071/BT9530402

Chen, L. H., Lin, C. H., and Chung, K. R. (2013). A nonribosomal peptide synthetase mediates siderophore production and virulence in the citrus fungal pathogen Alternaria alternata. Mol. Plant Pathol. 14, 497-505. doi: 10.1111/ mpp.12021

Choi, W., and Dean, R. A. (1997). The adenylate cyclase gene MACI of Magnaporthe grisea controls appressorium formation and other aspects of growth and development. Plant Cell 9, 1973-1983. doi: 10.2307/3870558

Choquer, M., Dekkers, K. L., Chen, H.-Q., Cao, L., Ueng, P. P., Daub, M. E., et al. (2005). The CTB1 gene encoding a fungal polyketide synthase is required for cercosporin biosynthesis and fungal virulence of Cercospora nicotianae. Mol. Plant Microbe Interact. 18, 468-476. doi: 10.1094/MPMI-18-0468

Conesa, A., and Gotz, S. (2008). Blast2GO: a comprehensive suite for functional analysis in plant genomics. Int. J. Plant Genomics 2008:619832. doi: 10.1155/ 2008/619832

Dalmais, B., Schumacher, J., Moraga, J., Pêcheur, L. E. P., Tudzynski, B., Collado, I. G., et al. (2011). The Botrytis cinerea phytotoxin botcinic acid requires two polyketide synthases for production and has a redundant role in virulence with botrydial. Mol. Plant Pathol. 12, 564-579. doi: 10.1111/j.1364-3703.2010. 00692.x

Dunn, M. F., Ramirez-Trujillo, J. A., and Hernandez-Lucas, I. (2009). Major roles of isocitrate lyase and malate synthase in bacterial and fungal pathogenesis. Microbiology 155, 3166-3175. doi: 10.1099/mic.0.030858-0

Egan, M. J., Wang, Z. Y., Jones, M. A., Smirnoff, N., and Talbot, N. J. (2007). Generation of reactive oxygen species by fungal NADPH oxidases is required for rice blast disease. Proc. Natl. Acad. Sci. U.S.A. 104, 11772-11777. doi: 10. 1073/pnas.0700574104

Garcia-Martinez, J., Adam, A. L., and Avalos, J. (2012). Adenylyl cyclase plays a regulatory role in development, stress resistance and secondary metabolism in Fusarium fujikuroi. PLoS ONE 7:e28849. doi: 10.1371/journal.pone.0028849

Giardine, B., Riemer, C., Hardison, R. C., Burhans, R., Elnitski, L., Shah, P., et al. (2005). Galaxy: a platform for interactive large-scale genome analysis. Genome Res. 15, 1451-1455. doi: 10.1101/gr.4086505

Goecks, J., Nekrutenko, A., Taylor, J., and Galaxy, T. (2010). Galaxy: a comprehensive approach for supporting accessible, reproducible, and transparent computational research in the life sciences. Genome Biol. 11:R86. doi: 10.1186/gb-2010-11-8-r86

Gryzenhout, M., Myburg, H., Merwe, N. A. V. D., Wingfield, B. D., and Wingfield, M. J. (2004). Chrysoporthe, a new genus to accommodate Cryphonectria cubensis. Stud. Mycol. 50, 119-142.

Hayden, K. J., Garbelotto, M., Knaus, B. J., Cronn, R. C., Rai, H., and Wright, J. W. (2014). Dual RNA-seq of the plant pathogen Phytophthora ramorum and its tanoak host. Tree Genet. Genomes 10, 489-502. doi: 10.1007/s11295-0140698-0
Heath, R. N., Gryzenhout, M., Roux, J., and Wingfield, M. J. (2006). Discovery of the canker pathogen Chrysoporthe austroafricana on native Syzygium spp. in South Africa. Plant Dis. 90, 433-438. doi: 10.1094/PD-90-0433

Hedden, P., Phillips, A. L., Rojas, M. C., Carrera, E., and Tudzynski, B. (2002). Gibberelin biosynthesis in plants and fungi: a case of convergent evolution. J. Plant Growth Regul. 20, 319-331. doi: 10.1007/s003440010037

Hottes, A. K., Meewan, M., Yang, D., Arana, N., Romero, P., McAdams, H. H., et al. (2004). Transcriptional profiling of Caulobacter crescentus during growth on complex and minimal Media. J. Bacteriol. 186, 1448-1461. doi: 10.1128/JB. 186.5.1448-1461.2004

Idnurm, A., and Howlett, B. J. (2002). Isocitrate lyase is essential for pathogenicity of the fungus Leptosphaeria maculans to canola (Brassica napus). Eukaryot. Cell 1, 719-724. doi: 10.1128/EC.1.5.719-724.2002

Klimpel, A., Grovoner, C. S., Williamson, B., Stewart, J. A., and Tudzynski, B. (2002). The adenylate cyclase BAC in Botrytis cinerea is required for full pathogenicity. Mol. Plant Pathol. 3, 439-450. doi: 10.1046/j.1364-3703.2002. 00137.x

Kubicek, C. P., Starr, T. L., and Glass, N. L. (2014). Plant cell wall-degrading enzymes and their secretion in plant-pathogenic fungi. Annu. Rev. Phytopathol. 52, 427-451. doi: 10.1146/annurev-phyto-102313-045831

Lee, S. H., Lee, J., Lee, S., Park, E. H., Kim, K. W., Kim, M. D., et al. (2009). GzSNF1 is required for normal sexual and asexual development in the ascomycete Gibberella zeae. Eukaryot. Cell 8, 116-127. doi: 10.1128/EC.00176-08

Lengeler, K. B., Davidson, R. C., D’Souza, C., Harashima, T., Shen, W.-C., Wang, P., et al. (2000). Signal transduction cascades regulating fungal development and virulence. Microbiol. Mol. Biol. Rev. 64, 746-785. doi: 10.1128/MMBR.64.4.746785.2000

Leslie, J. F. (2007). The Fusarium Laboratory Manual, eds J. F. Leslie and B. A. Summerell (Hoboken, NJ: Wiley), 5-13.

Lu, X., Hershey, D. M., Wang, L., Bogdanove, A. J., and Peters, R. J. (2015). An ent-kaurene-derived diterpenoid virulence factor from Xanthomonas oryzae pv. oryzicola. New Phytol. 206, 295-302. doi: 10.1111/nph.13187

Mangwanda, R., Myburg, A. A., and Naidoo, S. (2015). Transcriptome and hormone profiling reveals Eucalyptus grandis defense responses against Chrysoporthe austroafricana. BMC Genomics 16:319. doi: 10.1186/s12864-0151529-X

Martinez-Rocha, A. L., Roncero, M. I., Lopez-Ramirez, A., Marine, M., Guarro, J., Martinez-Cadena, G., et al. (2008). Rhol has distinct functions in morphogenesis, cell wall biosynthesis and virulence of Fusarium oxysporum. Cell Microbiol. 10, 1339-1351. doi: 10.1111/j.1462-5822.2008.01130.x

Mobius, N., and Hertweck, C. (2009). Fungal phytotoxins as mediators of virulence. Curr. Opin. Plant Biol. 12, 390-398. doi: 10.1016/j.pbi.2009.06.004

Morita, Y., Hyon, G. S., Hosogi, N., Miyata, N., Nakayashiki, H., Muranaka, Y., et al. (2013). Appressorium-localized NADPH oxidase B is essential for aggressiveness and pathogenicity in the host-specific, toxin-producing fungus Alternaria alternata Japanese pear pathotype. Mol. Plant Pathol. 14, 365-378. doi: $10.1111 / \mathrm{mpp} .12013$

Myburg, H., Gryzenhout, M., Wingfield, B. D., and Wingfield, M. J. (2002). $\beta$-Tubulin and histone $\mathrm{H} 3$ gene sequences distinguish Cryphonectria cubensis from South Africa, Asia, and South America. Can. J. Bot. 80, 590-596. doi: 10.1139/b02-039

Naidoo, R., Ferreira, L., Berger, D. K., Myburg, A. A., and Naidoo, S. (2013). The identification and differential expression of Eucalyptus grandis pathogenesisrelated genes in response to salicylic acid and methyl jasmonate. Front. Plant Sci. 4:43. doi: 10.3389/fpls.2013.00043

Oide, S., Moeder, W., Krasnoff, S., Gibson, D., Haas, H., Yoshioka, K., et al. (2006). NPS6, encoding a nonribosomal peptide synthetase involved in siderophore-mediated iron metabolism, is a conserved virulence determinant of plant pathogenic ascomycetes. Plant Cell 18, 2836-2853. doi: 10.1105/tpc.106. 045633

Ospina-Giraldo, M. D., Mullins, E., and Kang, S. (2003). Loss of function of the Fusarium oxysporum SNF1 gene reduces virulence on cabbage and Arabidopsis. Curr. Genet. 44, 49-57. doi: 10.1007/s00294-003-0419-y

Pearce, R. B. (1996). Antimicrobial defenses trees. New Phytol. 132, 203-233. doi: 10.1111/j.1469-8137.1996.tb01842.x

Penn, C. D., and Daniel, S. L. (2013). Salicylate degradation by the fungal plant pathogen Sclerotinia sclerotiorum. Curr. Microbiol. 67, 218-225. doi: 10.1007/ s00284-013-0349-y 
Proctor, R. H., Desjardins, A. E., Plattner, R. D., and Hohn, T. M. (1999). A polyketide synthase gene required for biosynthesis of fumonisin mycotoxins in Gibberella fujikuroi mating population A. Fungal Genet. Biol. 27, 100-112. doi: 10.1006/fgbi.1999.1141

Qin, X., Liu, J. H., Zhao, W. S., Chen, X. J., Guo, Z. J., and Peng, Y. L. (2012). Gibberellin 20-Oxidase Gene OsGA20ox3 regulates plant stature and disease development in rice. Mol. Plant Microbe Interact. 26, 227-239. doi: 10.1094/ MPMI-05-12-0138-R

Rabe, F., Ajami-Rashidi, Z., Doehlemann, G., Kahmann, R., and Djamei, A. (2013). Degradation of the plant defense hormone salicylic acid by the biotrophic fungus Ustilago maydis. Mol. Microbiol. 89, 179-188. doi: 10.1111/mmi.12269

Roux, J., Myburg, H., Wingfield, B. D., and Wingfield, M. J. (2003). Biological and phylogenetic analyses suggest that two Cryphonectria spp. cause cankers of Eucalyptus in Africa. Plant Dis. 87, 1329-1332. doi: 10.1094/PDIS.2003.87. 11.1329

Scheffer, J., Ziv, C., Yarden, O., and Tudzynski, P. (2005). The COT1 homologue CPCOT1 regulates polar growth and branching and is essential for pathogenicity in Claviceps purpurea. Fungal Genet. Biol. 42, 107-118. doi: 10.1016/j.fgb.2004.10.005

Segers, G. C., Regier, J. C., and Nuss, D. L. (2004). Evidence for a role of the regulator of G-protein signaling protein CPRGS-1 in Galpha subunit CPG-1-mediated regulation of fungal virulence, conidiation, and hydrophobin synthesis in the chestnut blight fungus Cryphonectria parasitica. Eukaryot. Cell 3, 1454-1463. doi: 10.1128/EC.3.6.1454-1463.2004

Segmüller, N., Kokkelink, L., Giesbert, S., Odinius, D., Kan, J. V., and Tudzynski, P. (2008). NADPH oxidases are involved in differentiation and pathogenicity in Botrytis cinerea. Mol. Plant Microbe Interact. 21, 808-819. doi: 10.1094/MPMI21-6-0808

Stergiopoulos, I., and de Wit, P. J. (2009). Fungal effector proteins. Annu. Rev. Phytopathol. 47, 233-263. doi: 10.1146/annurev.phyto.112408.132637

Sun, C. B., Suresh, A., Deng, Y. Z., and Naqvi, N. I. (2006). A multidrug resistance transporter in Magnaporthe is required for host penetration and for survival during oxidative stress. Plant Cell 18, 3686-3705. doi: 10.1105/tpc.105.037861

Takano, Y., Kikuchi, T., Kubo, Y., Hamer, J. E., Mise, K., and Furusawa, I. (2000). The Colletotrichum lagenarium MAP kinase gene CMK1 regulates diverse aspects of fungal pathogenesis. Mol. Plant Microbe Interact. 13, 374-383. doi: 10.1094/MPMI.2000.13.4.374

Tonukari, N. J., Scott-Craig, J. S., and Walton, J. D. (2000). The Cochliobolus carbonum SNF1 gene is required for cell wall-degrading enzyme expression and virulence on maize. Plant Cell 12, 237-247. doi: 10.1105/tpc.12.2.237

Tsuda, K., and Somssich, I. E. (2015). Transcriptional networks in plant immunity. New Phytol. 206, 932-947. doi: 10.1111/nph.13286

Tudzynski, B. (2005). Gibberellin biosynthesis in fungi: genes, enzymes, evolution, and impact on biotechnology. Appl. Microbiol. Biotechnol. 66, 597-611. doi: 10.1007/s00253-004-1805-1

Tudzynski, P., Heller, J., and Siegmund, U. (2012). Reactive oxygen species generation in fungal development and pathogenesis. Curr. Opin. Microbiol. 15, 653-659. doi: 10.1016/j.mib.2012.10.002

Turra, D., Segorbe, D., and Di Pietro, A. (2014). Protein kinases in plantpathogenic fungi: conserved regulators of infection. Annu. Rev. Phytopathol. 52, 267-288. doi: 10.1146/annurev-phyto-102313-050143

van Heerden, S. W. H., Amerson, V., Preisig, O., and Wingfield, M. J. (2005). Relative pathogenicity of Cryphonectria cubensis on Eucalyptus clones differing in their resistance to C. cubensis. Plant Dis. 89, 659-662. doi: 10.1094/PD-890659

Verberne, M. C., Verpoorte, R., Bol, J. F., Mercado-Blanco, J., and Linthorst, H. J. M. (2000). Overproduction of salicylic acid in plants by bacterial transgenes enhances pathogen resistance. Nat. Biotechnol. 18, 779-783. doi: $10.1038 / 77347$
Wang, X., Jiang, N., Liu, J., Liu, W., and Wang, G. L. (2014). The role of effectors and host immunity in plant-necrotrophic fungal interactions. Virulence 5, 722-732. doi: 10.4161/viru.29798

Wang, Z.-Y., Kershaw, M. J., Talbot, N. J., Thornton, C. R., and Debao, L. (2003). The glyoxylate cycle is required for temporal regulation of virulence by the plant pathogenic fungus Magnaporthe grisea. Mol. Microbiol. 47, 1601-1612. doi: 10.1046/j.1365-2958.2003.03412.x

Wayne, J. M., and Rollins, J. A. (2007). Deletion of the adenylate cyclase (sac1) gene affects multiple developmental pathways and pathogenicity in Sclerotinia sclerotiorum. Fungal Genet. Biol. 44, 521-530. doi: 10.1016/j.fgb.2006. 11.005

Westermann, A. J., Gorski, S. A., and Vogel, J. (2012). Dual RNA-seq of pathogen and host. Nat. Rev. Microbiol. 10, 618-630. doi: 10.1038/nrmicro2852

Wingfield, B. D., Ades, P. K., Al-Naemi, F. A., Beirn, L. A., Bihon, W., Crouch, J. A., et al. (2015). IMA Genome-F 4. Draft genome sequences of Chrysoporthe austroafricana, Diplodia scrobiculata, Fusarium nygamai, Leptographium lundbergii, Limonomyces culmigenus, Stagonosporopsis tanaceti, and Thielaviopsis punctulata. IMA Fungus 6, 233-248.

Wingfield, M. J., Slippers, B., Hurley, B. P., Coutinho, T. A., Wingfield, B. D., and Roux, J. (2008). Eucalypt pests and diseases: growing threats to plantation productivity. South. For. 70, 139-144. doi: 10.2989/SOUTH.FOR.2008.70.2.9. 537

Wingfield, M. J., Swart, W. J., and Abear, B. J. (1989). First record of Cryphonectria canker of Eucalyptus in South Africa. Phytophylactica 21, 311-313.

Winnenburg, R., Baldwin, T. K., Urban, M., Rawlings, C., Kohler, J., and Hammond-Kosack, K. E. (2006). PHI-base: a new database for pathogen host interactions. Nucleic Acids Res. 34, D459-D464. doi: 10.1093/nar/ gkj047

Yamauchi, J., Takayanagi, N., Komeda, K., Takano, Y., and Okuno, T. (2004). cAMP-PKA signaling regulates multiple steps of fungal infection cooperatively with Cmk1 MAP kinase in Colletotrichum lagenarium. Mol. Plant Microbe Interact. 17, 1355-1365. doi: 10.1094/MPMI.2004.17.12. 1355

Yang, D.-L., Li, Q., Deng, Y.-W., Lou, Y.-G., Wang, M.-Y., Zhou, G.-X., et al. (2016). Altered disease development in the eui mutants and eui overexpressors indicates that gibberellins negatively regulate rice basal disease resistance. Mol. Plant 1, 528-537. doi: 10.1093/mp/ssn021

Yang, G., Rase, M. S., Turgeon, B. G., and Yode, O. C. (1998). A polyketide synthase is required for fungal virulence and production of the polyketide T-Toxin. Plant Cell 8, 2139-2150. doi: 10.2307/3870419

Yi, M., Chi, M. H., Khang, C. H., Park, S. Y., Kang, S., Valent, B., et al. (2009). The ER chaperone LHS1 is involved in asexual development and rice infection by the blast fungus Magnaporthe oryzae. Plant Cell 21, 681-695. doi: 10.1105/tpc. 107.055988

Zhao, X., Mehrabi, R., and Xu, J. R. (2007). Mitogen-activated protein kinase pathways and fungal pathogenesis. Eukaryot. Cell 6, 1701-1714. doi: 10.1128/ EC.00216-07

Conflict of Interest Statement: The authors declare that the research was conducted in the absence of any commercial or financial relationships that could be construed as a potential conflict of interest.

Copyright (c) 2016 Mangwanda, Zwart, van der Merwe, Moleleki, Berger, Myburg and Naidoo. This is an open-access article distributed under the terms of the Creative Commons Attribution License (CC BY). The use, distribution or reproduction in other forums is permitted, provided the original author(s) or licensor are credited and that the original publication in this journal is cited, in accordance with accepted academic practice. No use, distribution or reproduction is permitted which does not comply with these terms. 